\title{
COMPARISON OF IMMUNOCHROMATOGRAPHIC TEST AND MICROSCOPY IN THE DETECTION OF SOME ENTERIC PROTOZOA IN STOOL SAMPLES
}

By

\section{MOHAMED MOHAMED ATIA, MAGDA ABDEL-FATAH ELSETTAWY, GHADA MAHMOUD FATHY, MARWA AHMED SALAMA AND SHAIMAA ELSAYED MOHAMED METWALLY ASHOUSH}

\section{Department of Medical Parasitology, Faculty of Medicine, Zagazig University, Egypt.} Abstract

Infection with pathogenic intestinal protozoa as Giardia lamblia, Entamoeba histolytica and Cryptosporidium parvum cause considerable gastrointestinal morbidity, malnutrition and mortality worldwide, especially among young children in developing countries. The present study was carried out on 71 cases (44 males \& 27 females) chosen from Pediatric and Internal Medicine Inpatient and Outpatient Clinics of Zagazig University Hospitals, complaining of different gastrointestinal troubles with an age range of 6-60 years. Also, 20 apparently healthy individuals (11 males \& 9 females) cross matched were considered as a control negative group. All stool samples were examined by direct wet smears, concentration techniques, staining of the smears using trichrome stain and Modified Ziehl-Neelsen method. Copro-antigen detection in faecal sample was by using quick immunochromatographic test. A total of 71 cases suffering from different GIT manifestations showed G. lamblia (30.7\%), Cryptosporidium parvum (19.8\%), Entamoebahistolytica/E. dispar (11\%) and mixed infection of three protozoa (6.6\%). However, by copro-antigen G. lamblia was positive in (31.8\%) of C. parvum in $(20.9 \%)$; E. histolytica/E. dispar in $(11 \%)$ of cases. Immunochromatography/copro-antigen test recorded sensitivity and specificity of $(100 \%)$ and $(96.6 \%)$ respectively in G. lamblia detection. For C. parvum, sensitivity was $(100 \%)$ and specificity was $(97.1 \%)$ while for E. histolytica/E. dispar, sensitivity and specificity were $(100 \%)$ for both. Immunochromatographic assay proved to be simple, easy and useful in confirming absence or the presence of intestinal protozoan infection in clinically suspected cases with negative stool examination.

Keywords: Egypt, Zagazig, Patients, Immunochromatographic test, Microscopy, Intestinal protozoa

G. lamblia is the commonest cause of waterborne diarrhea worldwide. Although, it causes as a self-limiting acute infection, but evidence suggested that acute giardiasis may lead to the development of chronic functional gastrointestinal disorders, such as postinfectious irritable bowel syndrome (IBS) and functional dyspepsia, by unknown mechanisms (Spiller and Garsed, 2009; Cotton et al, 2011). E. histolytica have a worldwide distribution, particularly in tropical and subtropical areas, and is one of the leading parasitic burdens in developing countries, contributing to 50 million cases and an estimated 100,000 deaths annually (AguilarDiaz et al, 2011; Morf and Singh, 2012). C. parvum is a zoonotic protozoan parasite, which oocysts are resistant to chlorinated water and can survive in aquatic environ-

\section{Introduction}

Diarrheal diseases were ranked the second cause of morbidity and mortality in children in the developing countries (WHO, 2005), as a major cause of morbidity and mortality worldwide particularly where poor sanitary and hygienic conditions exist (Walker et al, 2012). Diarrhea is defined by having three or more loose or liquid stool per day, it can be caused by different bacteria, viruses and parasites and can spread through contaminated food, drinking water or from person to person as a result of poor hygiene (WHO, 2014). The most common parasitic causes of acute diarrhea are the intestinal protozoa of which Entamoeba histolytica; Giardia lamblia and Cryptosporidium parvum are considered the most important (Kourenti et al, 2007). 
our, odour and the presence of blood or mucous) and microscopically by direct smear examination both saline and iodine wet mounts (Fleck and Moody, 1988), Zinc sulphate centrifugal floatation (Beaver GIT, 1984), Formol-ether sedimentation (Cheesbrough, 2009), the slides were examined using a low-power objective $(10 \times)$ and high-power objective $(40 \times)$ respectively. Some smears prepared from formol ether techniques were fixed using Schaudinn's fixative to be stained later by modified Ziehl-Neelsen method (Cheesbrough, 2000), and trichrome staining technique (Cheesbrough, 1987).

Quick immunochromatographic test (RIDA®QUICK Cryptosporidium/ Giardia/ Entamoeba Combi): It is a single-step immunochromatographic test, where specific antibodies against each parasite attach themselves to green (Entamoeba specific), red (Giardia specific) or blue (Cryptosporidium specific) latex particles. Band appears, depending on the antigens present in the sample. According to the manufactures guide, Stool samples and all reagents were brought to room temperature before use, each sample ( $100 \mu 1$ from liquid stool or $50 \mathrm{mg}$ from solid stool samples) was well mixed with one $\mathrm{ml}$ from the extraction buffer using the vortex mixer, and then they were left for at least three minutes to allow the homogenized suspension to precipitate. From the clearly formed supernatant $200 \mu 1-500 \mu 1$ were transferred into other clean tubes. A test strip was immersed in each tube. The test result can be read off after 10 minutes. A maximum of four bands should appear in the following order from the sample-absorption site: blue, red, green and crimson (control). If the control band is missing, the test is invalid and cannot be evaluated.

Statistical analysis: Data were recorded, calculated, tabulated and statistically analyzed using statistical computer program SPSS version 16 under windows 7. ments for a long time (Chauret et al, 1998). The association of Cryptosporidium with waterborne-related outbreaks of diarrhea gave parasite a risky importance (Shaapan and Khalil, 2014).

Although microscopic examination of stools for detection of cysts, oocysts and trophozoites remains the diagnostic method of choice, as it is simple and of low cost, it requires technical expertise, time consuming and does not allow determination of the parasite species or genotype (Ryan and Cacciò, 2013). Antigen detection assays, such as enzyme immunoassays (EIAs) and immunochromatography (IC), for detection of $C$. parvum, G. lamblia and E. histolytica/dispar were developed (Garcia et al, 2003). The triple immunochromatographic tests proved to be a simple, fast and additive method for the simultaneous diagnosis of these parasites in stool samples. Also, it requires little exercise and can be used in individual base for timely screening (Weitzel et al, 2006).

The present study was designed to evaluate the sensitivity and specificity of the triple immunochromatographic test in relation to direct microscopic examination for detection of most common enteric protozoa ( $G$. lamblia, C. parvum \&E. histolytica/E. dispar) in stool samples of GIT patients.

\section{Subjects, Materials and Methods}

The present work was carried out on 71 cases (44 males and 27 females) attending Pediatric and Internal Medicine Inpatient and Outpatient Clinics of Zagazig University Hospital, and complaining of different gastrointestinal troubles with an age range of 660 years. Also 20 healthy cross-matched individuals (11 males \& 9 females) were utilized as control negative group. For all (patients and controls), stool samples were collected on three consecutive days. Each sample was divided into 2 parts one kept fresh for stool examination and the other was kept at $(-20)$ for antigen testing by the quick immunochromatographic test.

Stool examination: Each sample was examined macroscopically (consistency, col- 
alone. GIV: Patients with mixed infection of the three protozoan parasites. GV: patients negative for these protozoan parasites but infected with other parasites. GVI: Healthy group as control who were negative for all parasites.

\section{Results}

According to microscopic examination cases were divided into six groups as follow: GI: patients infected with G. lamblia alone. GII: patients infected with $C$. parvum alone. GIII: patients infected with Entamoeba

Table 1: Incidence of three protozoan parasites according to age among corresponding group

\begin{tabular}{|c|c|c|c|c|c|c|c|c|c|c|}
\hline \multirow[b]{2}{*}{ Age } & \multicolumn{2}{|c|}{ GI $(n=28)$} & \multicolumn{2}{|c|}{ GII $(n=18)$} & \multicolumn{2}{|c|}{ GIII $(n=10)$} & \multicolumn{2}{|c|}{ GIV $(n=6)$} & \multirow{2}{*}{$\chi^{2}$} & \multirow{2}{*}{$\mathrm{P}$} \\
\hline & $\mathrm{N}$ & $\%$ & $\mathrm{~N}$ & $\%$ & $\mathrm{~N}$ & $\%$ & $\mathrm{~N}$ & $\%$ & & \\
\hline $6-15$ & 17 & 60.7 & 9 & 50 & 5 & 50 & 4 & 66.7 & \multirow{3}{*}{3.20} & \multirow{3}{*}{$\begin{array}{c}0.78 \\
\mathrm{NS}\end{array}$} \\
\hline $16-30$ & 7 & 25 & 6 & 33.3 & 2 & 20 & 2 & 33.3 & & \\
\hline $31-60$ & 4 & 14.3 & 3 & 16.7 & 3 & 30 & 0 & 0 & & \\
\hline$\chi^{2 \#}$ & \multicolumn{2}{|c|}{9.93} & \multicolumn{2}{|c|}{3} & \multicolumn{2}{|c|}{1.4} & \multicolumn{2}{|c|}{0.67} & & \\
\hline $\mathrm{P}$ & \multicolumn{2}{|c|}{$0.007 *$} & \multicolumn{2}{|c|}{$0.22 \mathrm{NS}$} & \multicolumn{2}{|c|}{$0.50 \mathrm{NS}$} & \multicolumn{2}{|c|}{$0.42 \mathrm{NS}$} & & \\
\hline
\end{tabular}

Table 2: Incidence of three protozoan parasites according to sex among corresponding group.

\begin{tabular}{|c|c|c|c|c|c|c|c|c|c|c|}
\hline \multirow[b]{2}{*}{ Sex } & \multicolumn{2}{|c|}{ GI $(n=28)$} & \multicolumn{2}{|c|}{ GII $(n=18)$} & \multicolumn{2}{|c|}{ GIII $(n=10)$} & \multicolumn{2}{|c|}{ GIV $(n=6)$} & \multirow{2}{*}{$\chi^{2}$} & \multirow{2}{*}{$\mathrm{P}$} \\
\hline & $\mathrm{N}$ & $\%$ & $\mathrm{~N}$ & $\%$ & $\mathrm{~N}$ & $\%$ & $\mathrm{~N}$ & $\%$ & & \\
\hline Male & 18 & 64.3 & 10 & 55.6 & 6 & 60 & 3 & 50 & \multirow{2}{*}{0.61} & \multirow{2}{*}{$\begin{array}{c}0.90 \\
\text { NS }\end{array}$} \\
\hline Female & 10 & 35.7 & 8 & 44.4 & 4 & 40 & 3 & 50 & & \\
\hline
\end{tabular}

Table 3: Incidence of three protozoan parasites according to residence among corresponding group.

\begin{tabular}{|c|c|c|c|c|c|c|c|c|c|c|}
\hline \multirow[b]{2}{*}{ Residence } & \multicolumn{2}{|c|}{ GI $(n=28)$} & \multicolumn{2}{|c|}{ GII $(n=18)$} & \multicolumn{2}{|c|}{ GIII $(n=10)$} & \multicolumn{2}{|c|}{$\operatorname{GIV}(n=6)$} & \multirow[b]{2}{*}{$\chi^{2}$} & \multirow[b]{2}{*}{$P$} \\
\hline & $\mathrm{N}$ & $\%$ & $\mathrm{~N}$ & $\%$ & $\mathrm{~N}$ & $\%$ & $\mathrm{~N}$ & $\%$ & & \\
\hline Rural & 18 & 64.3 & 12 & 66.7 & 6 & 60 & 3 & 50 & 0.6 & 0.89 \\
\hline Urban & 10 & 35.7 & 6 & 33.3 & 4 & 40 & 3 & 50 & 0 & NS \\
\hline
\end{tabular}

Table 4: Comparison between microscopic examination and immunochromatographic test (ICT) among groups:

\begin{tabular}{|c|c|c|c|c|c|c|}
\hline \multirow{2}{*}{ Variable } & \multicolumn{2}{|c|}{ Microscopy $(n=91)$} & \multicolumn{2}{|c|}{$\operatorname{ICT}(n=91)$} & \multirow[b]{2}{*}{ Kappa } & \multirow[b]{2}{*}{$\mathrm{P}$} \\
\hline & No & $\%$ & No & $\%$ & & \\
\hline Giardia lamblia & 28 & 30.7 & 29 & 31.8 & & \\
\hline Cryptosporidium parvum & 18 & 19.8 & 19 & 20.9 & & \\
\hline Entamoeba histolytica/E. dispar & 10 & 11 & 10 & 11 & & \\
\hline Mixed & 6 & 6.6 & 7 & 7.7 & & \\
\hline G. lamblia + C. parvum & 2 & 2.2 & 3 & 3.3 & & \\
\hline E. histolytica/E. dispar + G. lamblia & 1 & 1.1 & 1 & 1.1 & & \\
\hline E. histolytica/E. dispar + C. parvum. & 2 & 2.2 & 2 & 2.2 & & \\
\hline E. histolytica/E. dispar + G. lamblia + C. parvum. & 1 & 1.1 & 1 & 1.1 & & \\
\hline Others & 9 & 9.9 & 0 & 0 & 0.82 & $<0.001 * *$ \\
\hline Entamoeba coli & 3 & 3.3 & - & & 0.82 & $<0.001 .21$ \\
\hline Blastocystis hominis & 3 & 3.3 & - & & & \\
\hline Enterobius egg & 2 & 2.2 & - & & & \\
\hline Srongyloides stercoralis larva & 1 & 1.1 & - & & & \\
\hline Negative & 20 & 22 & 26 & 28.6 & & \\
\hline
\end{tabular}

Table 5: Validity of ICT in diagnosis of Giardia lamblia in comparison to microscopy as Gold standard:

\begin{tabular}{|c|c|c|c|}
\hline \multirow{2}{*}{ ICT: } & \multicolumn{2}{|c|}{ Microscopy } & \multirow{2}{*}{ Total } \\
\hline & $+\mathrm{ve}$ & $-\mathrm{ve}$ & \\
\hline$+\mathrm{ve}$ & 32 & 2 & 34 \\
\hline -ve & 0 & 57 & 57 \\
\hline Total & 32 & 59 & 91 \\
\hline Validity & \multicolumn{3}{|c|}{$\begin{array}{cc}\text { Sensitivity: } 100 \% & \text { Specificity: } 96.6 \% \\
\text { PPV: } 94.1 \% & \text { NPV: } 100 \%\end{array}$} \\
\hline Accuracy & \multicolumn{3}{|c|}{$97.8 \%$} \\
\hline
\end{tabular}


Table 6: Validity of ICT in diagnosis of C. parvum infection in comparison to microscope as Gold standard:

\begin{tabular}{|l|c|c|r|}
\hline \multirow{2}{*}{ ICT: } & +ve & \multirow{2}{*}{ Total } \\
\cline { 2 - 4 } & 23 & $-\mathrm{ve}$ & 25 \\
\hline +ve & 0 & 66 & 66 \\
\hline -ve & 23 & 68 & 91 \\
\hline Total & Sensitivity: $100 \% \quad$ Specificity: $97.1 \%$ \\
\hline \multirow{2}{*}{ Validity } & PPV: $92 \%$ & NPV: $100 \%$ \\
\hline Accuracy & \multicolumn{2}{|c|}{$97.8 \%$} \\
\hline
\end{tabular}

Table 7: Validity of ICT in diagnosis of E. histolytica/E. dispar i in comparison to microscope as Gold standard:

\begin{tabular}{|l|c|c|l|}
\hline \multirow{2}{*}{ ICT: } & \multicolumn{2}{|c|}{ Microscopey } & \multirow{2}{*}{ Total } \\
\cline { 2 - 4 } & + ve & - ve & \\
\hline +ve & 14 & 0 & 14 \\
\hline -ve & 0 & 77 & 77 \\
\hline Total & 14 & Specificity: $100 \%$ \\
\hline \multirow{2}{*}{ Validity } & Sensitivity: $100 \%$ & NPV: $100 \%$ \\
& PPV: $100 \%$ & $100 \%$ & 91 \\
\hline Accuracy & \multicolumn{3}{|c|}{} \\
\hline
\end{tabular}

\section{Discussion}

Diarrheal diseases are one of the causes of morbidity and mortality in developing countries, especially in malnourished children, patients with chronic diseases and immunocompromised (Abdel-Hafeez et al, 2012). Cryptosporidium, Giardia duodenalis and Entamoeba histolytica were recognized as causative agents of diarrheal disease worldwide (Stark et al, 2009). These protozoa could be transmitted through contaminated water or foods, person to person, and by zoonotic transmission (Thompson and Smith, 2011).

In the present study, children were 6-15 years old recorded the highest infection percentage $(60.7 \%)$ followed by $16-30$ years old $(25 \%)$ and then $30-60$ years $(14.3 \%)$ with significant difference and males (64.3\%) were more than females $(35.7 \%)$, but without significant difference $(\mathrm{p}>0.05)$. These agreed with Helmy et al. (2009) who found that the highest percentage of infection in patients 10 to 20 years old $(56.3 \%)$ among 41 Egyptian patients with $G$. lamblia aged between 0-65 years old. Bernawi et al. (2013) also found that the highest infection rate was in the same age group with males were commonly affected more than females without significant difference. This could be explained by this group are fully independ- ent in toilet use and more involved in outdoor activities which might lead to Giardia transmission. The result agreed with worldwide reports suggesting that giardiasis is one of the major health problems among population of younger age groups (Anuar et al, 2012). In contrast, De Lucio et al. (2015) found that the highest infection rate of symptomatic giardiasis was in the age group 0-4 years, and that males were affected more than females. This could confirm that infants and young children are most susceptible to the infection and males are commonly affected most probably due to their wide range of movement in the society. On the other hand, Zaglool et al. (2011)in Saudi Arabia stated that the giardiasis incidence was equal in both sexes.

In the present study infection was higher in patients living in rural areas, but without significant difference $(\mathrm{p}>0.05)$. Almerie et al. (2008) reported that children in rural areas were more prone to G. lamblia infection than those living in urban areas, but without significant difference. Mbuh et al. (2011) in south-west Cameroon reported higher infection with $E$. histolytica in rural $(34.0 \%)$ than urban areas (18.4\%). Also, Mohammad et al. (2012) in Egypt reported that the prevalence of parasites was more common in rural areas. Mathew et al. (2014) in Nigeria found 
that prevalence of $C$. parvum was higher among children in rural areas. On the other hand, Ahmed (2013) in Gharbia Governorate found high prevalence of E. histolyti$c a$ and G. lamblia in urban than rural communities. The high percentage of intestinal protozoan infections in rural areas may be due to poverty, poor living and hygienic conditions, drinking of underground water which is contaminated with sewage, compared to urban areas, also the extensive use of human and animal excreta as fertilizer in agriculture, the household wastewater is thrown in irrigation channels in addition to the close contact with animals (Pham-Duc et al, 2011).

In the present study, diarrhea alone was found to be the commonest clinical symptom in patients with $G$. lamblia $50 \%, C$. parvum 50\% and mixed infection 100\% while in E. histolytica/E. dispar group, diarrhea alone was found in $20 \%$ of cases with significant difference between them. This might be due to the fact that G. lamblia and $C$. parvum inhabit the small intestine, and thus expected to be present with diarrhea. This agreed with Hawash et al. (2015) who reported stated that acute and transient diarrhea in $71 \%$ of intestinal protozoan infection.

In the present study, stool samples were examined by wet smear, concentration techniques, staining with both trichrome and modified Ziehl-Neelsen and antigen detection using immunochromatography. Microscopic examination was taken as the gold standard and the sensitivity and specificity of the immunochromatography test was calculated in comparison with this fact. Microscopic examination of stool samples showed that the most frequent parasite detected was G. lamblia $(30.7 \%)$ followed by C. parvum $(19.8 \%)$ and then E. histolytica/E. dispar $(11 \%)$. There were also mixed infections of the three protozoan parasites $(6.6 \%)$. Parasites other than the parasites under study were found including Entamoeba coli (3.3\%), Blastocystis hominis (3.3\%), Enter- obius (2.2\%) and Strongyloides stercoralis (1.1\%). The twenty samples (controls) were negative for all parasites.

Gaafer (2011) in Alexandria found that $G$. lamblia was the commonest followed by $C$. parvum and then E. histolytica/E. dispar among 100 patients attended the outpatient clinic of Alexandria University Hospitals. But, Goni et al. (2012) found that E. histolytica/E. dispar $(25.63 \%)$ was the commonest followed by G. lamblia (19.38\%) and then $C$. parvum $(13.75 \%)$, which might be due to different in environmental conditions

In the present study none was positive by copro-antigen immunochromatographic test, that is to say no cross reactivity occurred with copro-anitgen with parasites other than three dealt with. Also, Gaafer (2011) reported that Triage Micro parasite Panel test did not diagnose any parasite other than G. lamblia, C. parvum and E. histolytica/E. dispar with no cross reactivity with other intestinal parasites. The triple ICT for $G$. lamblia showed that the sensitivity was $100 \%$, the specificity was $96.6 \%$, the positive predictive value was (PPV) $94.1 \%$ and the negative predictive value (NPV) was $100 \%$. Goni et al. (2012) reported that the sensitivity and specificity for the triple ICT were $96.8 \%$ and $99.5 \%$ respectively for $G$. lamblia detection. Also, Swierczewski et al. (2012) used triage parasite panel on 266 samples in Kenya and found that the sensitivity $100 \%$ and specificity $100 \%$ in detection of $G$. lamblia.

When using triple ICT for the detection of C. parvum, sensitivity was $100 \%$, specificity was $97.1 \%$, PPV was $92 \%$ and NPV was 100\%. Regnath et al. (2006) obtained 100\% sensitivity and specificity in C. parvum diagnosis with Rida ${ }^{\circledR}$ Quick Crypto/Giardia combi. Others, with the same test, in diagnosis Cryptosporidium and Giardia got $92 \%$ \& 97\% sensitivity (Gutiérrez-Cisneros et al, 2011). On the other hand, Goni et al. (2012) reported lower results in detection of $C$. parvum by the triage where the sensitivity was 72.7\%. Swierczewski et al. (2012) found lower $73 \%$ sensitivity in C. parvum detec- 
tion, which might be due to difference in the monoclonal antibodies used.

For E. histolytica /E. dispar, the triple ICT showed that the sensitivity was $100 \%$, the specificity was $100 \%$, PPV was $100 \%$ and NPV was $100 \%$. This agreed with Swierczewski et al. (2012) in Kenya who mentioned that the sensitivity and the specificity were $100 \%$ when compare the triage ICT with microscopy in detection of the three parasites in stool samples. But, lower results reported by Goni et al. (2012), which might be due to the fact that they used PCR as standard reference.

A limitation to the Triple ICT as with microscopic examination is that both are unable to differentiate between the pathogenic $E$. histolytica and the nonpathogenic $E$. dispar, so this requires use confirmatory test to differentiate in between as ELISA \& PCR.

\section{Conclusion}

The Triple ICT is sensitive and specific for the detection of G. lamblia, C. parvum and E. histolytica/E. dispar. The kit could be used as a screening tool in wide-scale prevalence studies or in suspected outbreak investigations because it is rapid and simple procedure and don't need training. The Triage Micro Parasite Panel could be used in conjunction with ordinary microscopic examination in medical laboratories or possibly as an alternative method.so we recommend their use in epidemiological studies in control programs.

Authors contribution: Atia MM, proposed the idea, Elsettawy MA and Fathy GM, shared in the design, reviewed practical work, wrote and reviewed manuscript, Salama MA, shared in writing manuscript, Ashoush SE, shared in practical work and writing manuscript as well.

\section{References}

Abdel-Hafeez, EH, Ahmad, AK, Ali, BA, Moslam, FA, 2012: Opportunistic parasites among immunosuppressed children in Minia district, Egypt. Korean J. Parasitol. 50:57-62.

Aguilar-Diaz, H, Carrero, JC, Arguello-Garcia, R, Laclette, JP, Morales-Montor, J, 2011: Cyst and encystment in protozoan parasites: op- timal targets for new life-cycle interrupting strategies? Trends Parasitol, 27:450-58.

Ahmed, WF, 2013: Intestinal parasites among primary school children in urban and rural Tanta, Gharbia, Governorate, Egypt. Egypt. J. Exp. Biol. Zool. 9, 2:257-62.

Almerie, MQ, Azzouz, MS, Abdessamad, MA, Mouchli, MA, Sakbani, MW, et al, 2008: Prevalence and risk factors for giardiasis among primary school children in Damascus, Syria. Saudi Med. J. 29:234-40.

Anuar, TS, Al-Mekhlafi, HM, Ghani, MK, Osman, E, Yasin, AM, et al, 2012: Giardiasis among different tribes of Orang Asli in Malaysia: highlighting the presence of other family members infected with Giardia intestinalis as a main risk factor. Int. J. Parasitol., 42:871-80.

Beaver, PC, Jung, RC, Cupp, EW, 1984: In: Clinical Parasitology. $9^{\text {th }}$ ed. Lea and Febiger, Philadelphia, U.S.A.

Bernawi, AAA, Omar, SEM, Kti, SEO, 2013: Prevalence of Giardia lamblia in humans visited central laboratory of Sebha Province. Int. J. Eng. Sci. Innov. Technol. 2, 3:169-72.

Chauret, C, Nolan, K, Chen, P, Springthorpe, S, Sattar, S, 1998: Aging of Cryptosporidium parvum oocysts in river water and their susceptibility to disinfection by chlorine and monochloramine. Can. J. Microbiol. 44:1154-60.

Cheesbrough, M, 1987: Medical Laboratory Manual for Tropical Countries. ELBS Tropical Health Technology Butterworth.

Cheesbrough, M, 2000: In: District Laboratory Practice in Tropical Countries. Part I- Cambridge University Press.

Cheesbrough, M, 2009: In: District Laboratory Practice in Tropical Countries. New York, Cambridge University Press.

Cotton, JA, Beatty, JK, Buret, AG, 2011: Host parasite interactions and pathophysiology in $\mathrm{Gi}$ ardia. Int. J. Parasitol. 41, 9:925-33.

De Lucio, A, Martínez-Ruiz, R, Merino, FJ, Bailo, B, Aguilera, M, et al, 2015: Molecular Genotyping of Giardia duodenalis Isolates from symptomatic individuals attending two major public hospitals in Madrid, Spain. PLoS One 10, 12:0143981.

Fleck, SL, Moody, A.H., 1988: In: Diagnostic technique in Medical Parasitology. $1^{\text {st }}$ ed. Butterworth\& Co. Ltd.

Gaafar, MR, 2011: Evaluation of enzyme immunoassay techniques for diagnosis of the most common intestinal protozoa in fecal samples.Int. 
J. Infect. Dis. 15:541-4.

Garcia, LS, Shimizu, RY, Novak, S, Carroll, M, Chan, F, 2003: Commercial assay for detection of Giardia lamblia and Cryptosporidium parvum antigens in human fecal specimens by rapid solid-phase qualitative immunochromatography. J. Clin. Microbiol. 41, 1:209-12.

Goñi, P, Martín, B, Villacampa, M, García, A, Seral, C, et al, 2012: Evaluation of an immunochromatographic dip strip test for simultaneous detection of Cryptosporidium spp., Giardia duodenalis, and Entamoeba histolytica antigens in human fecal samples. Eur. J. Clin. Microbiol. Infect. Dis. 31:2077-82.

Gutiérrez-Cisneros, MJ, Ruiz, R, Subirats, M, Merino, FJ, Millán, R, et al, 2011: Assessment of two commercially available immunochromatographic assays for a rapid diagnosis of Giardia duodenalis and Cryptosporidium spp. in human fecal specimens. Enferm. Infec. Microbiol. Clin. 29, 3:201-3.

Hawash, YA, Dorgham, LSh, Amir, EM, Sharaf, OF, 2015: Prevalence of intestinal protozoa among Saudi patients with chronic renal failure: A case-control study. J. Trop. Med. 563478, http://dx.doi.org/10.1155/2015/563478.

Helmy, MF, Hisham, S, Abdel-Fattah, HS, Rashed, L, 2009: Real-Time Pcr/Rflp assay to detect Giardia intestinalis genotypes in human isolates with diarrhea in Egypt. J. Parasitol. 95, 4:1-5.

Kourenti, C, Karanis, P, Smith, H, 2007: Waterborne transmission of protozoan parasites: a worldwide review of outbreaks and lessons learnt. J. Water Hlth, 5, 1:1-38.

Mathew, AO, David, OO, Olubunmi, FI, Mosunmola, OJ, Tiamiyu, AR, et al, 2014: Infection Rate of Cryptosporidium parvum among Diarrhea Children in Ibadan, Oyo State, Nigeria. Sch. J. App. Med. Sci. 2, 6D:3127-31.

Mbuh, JV, Ntonifor, NH, Ojong, J, 2011: The epidemiology of soil-transmitted helminth and protozoan infections in south-west Cameroon. J. Helminthol. 23:1-8.

Mohammad, AE, Khaled, AM, Abu El-Nour, MF, Saad, MY, et al, 2012: The prevalence and associated risk factors of intestinal parasitic infect ions among school children living in rural and urban communities in Damietta Governorate, Egypt. Acad. Arena 4, 5:90-7.

Morf, L, Singh, U, 2012: Entamoeba histolyti$c a$ : A snapshot of current research and methods for genetic analysis. Curr. Opin. Microbiol.
15:469-75.

Pham-Duc, P, Nguyen-Viet, H, Hattendorf, J, Zinsstag, J, Dac-Cam, P, et al, 2011: Risk factors for Entamoeba histolytica infection in an agricultural community in Hanam Province, Vietnam. Parasites Vectors 4:102-8.

Regnath, T, Klemm, T, Ignatius, R, 2006: Rapid and accurate detection of Giardia lamblia and Cryptosporidium spp. antigens in human fecal specimens by new commercially available qualitative immunochromatographic assays. Eur. J. Clin. Microbiol. Infect. Dis. 25, 12:807-9.

Ryan, U, Cacciò, SM, 2013: Zoonotic potential of Giardia. Int. J. Parasitol. 43:943-56.

Shaapan, R, Khalil, F, 2014: Zoonotic significance of cryptosporidiosis: Lambert Academic Publishing, Saarbrucken, Germany.

Spiller, R, Garsed, K, 2009: Post infectious irritable bowel syndrome. Gastroenterology 136, 6:1979-88.

Stark, D, Barratt, JLN, Van Hal, S, Marriott, DJ, Harkness, J, et al, 2009: Clinical significance of enteric protozoa in immunosuppressed human population. Clin. Microbiol. Rev. 22: 634 -50 .

Swierczewski, B, Odundo, E, Ndonye, J, Kirera, R, Odhiambo, C, et al, 2012: Comparison of the triage micro parasite panel and microscopy for the detection of Entamoeba histolytica/Entamoeba dispar, Giardia lamblia, and Cryptosporidium parvum in stool samples collected in Kenya, J. Trop. Med., doi:10.1155/ 564721.

Thompson, RCA, Smith, A, 2011: Zoonotic enteric protozoa. Vet. Parasitol. 182:70-8.

Walker, CLF, Aryee, MJ, Boschi-Pinto, C, Black, RE, 2012: Estimating diarrhea mortality among young children in low and middle income countries. PLoS One 7, 1:e29151.

Weitzel, T, Dittrich, S, Möhl, I, Adusu, E, Jelinek, T, 2006: Evaluation of seven commercial antigen detection tests for Giardia and Cryptosporidium in stool samples. Clin. Microbiol. Infect. 12:656-9.

WHO, 2005: Making Every Mother and Child Count, WHO Report, Geneva, Switzerland.

WHO, 2014: Diarrheal disease Fact sheet no. 330 .

Zaglool, DAM, Khodari, YAW, Gazzaz, ZJ, Khalid, O, Dhafar, KO, et al, 2011: Prevalence of intestinal parasites among patients of Al-Noor Specialist Hospital, Makkah, Saudi Arabia. Oman Med. J. 26, 3:182-5. 


\section{Explanation of figures}

F.1: Stool smear: a- stained with Lugol's iodine showing G. lamblia trophozoite (x400), b- stained with Lugol's iodine showing E. histolytica/E. dispar cyst (x400), c- stained with trichrome stain showing G. lamblia cyst (x1000), d- stained with trichrome showing E. histolyticalE. dispar cyst (x1000), e- stained with MZN stain showing C. parvum oocyst (x1000). Fig. 2: Correlation between group and clinical presentation.

Fig. 3: Test strip with positive for E. histolytica/E. dispar, G. lamblia \& C. parvum (crimson, green, red and blue bands).
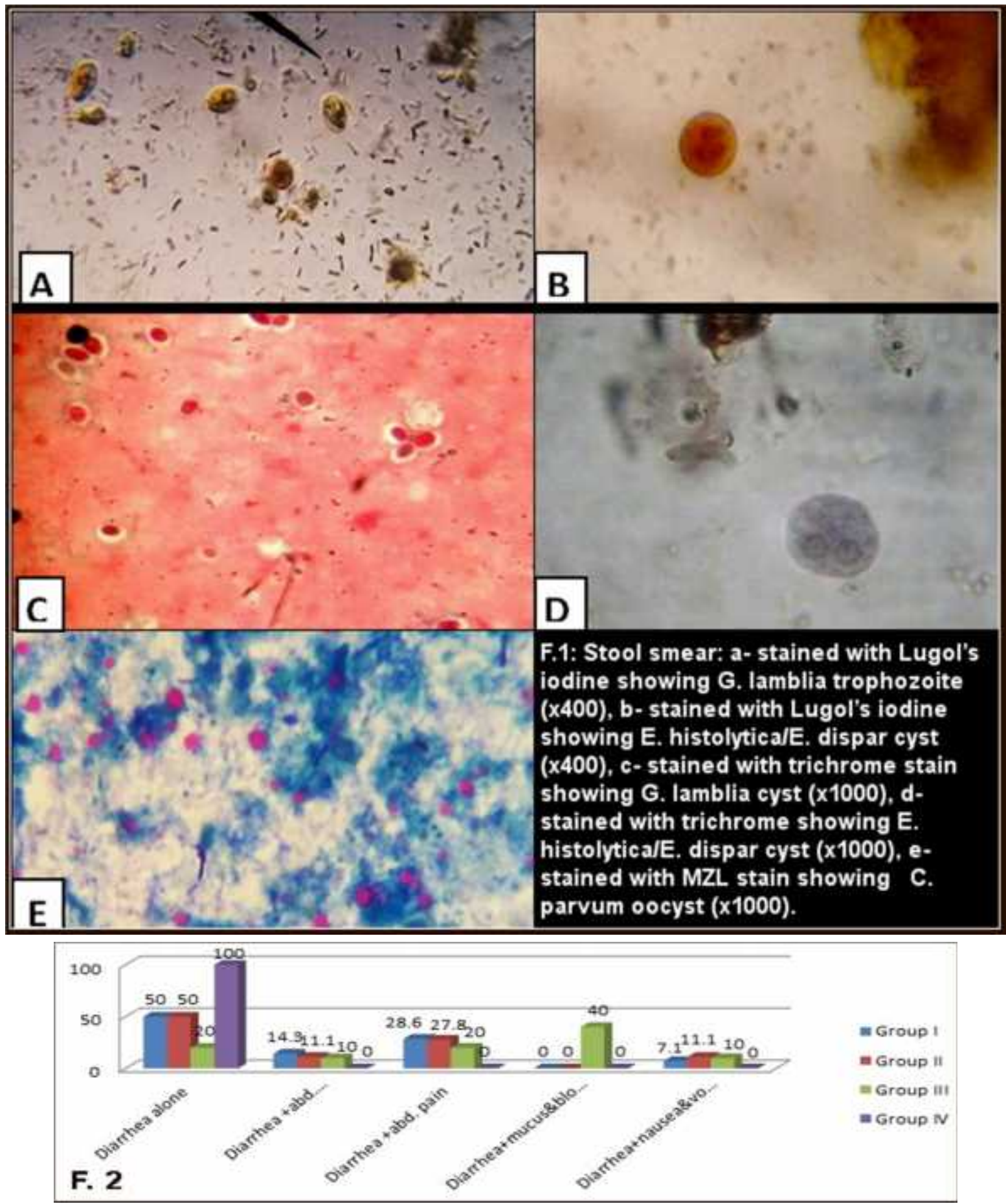

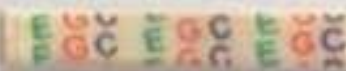

F. 3 
